Article

\title{
The Fourth Wave of Digitalization and Public Transport: Opportunities and Challenges
}

\author{
Paul Davidsson *, Banafsheh Hajinasab, Johan Holmgren, Åse Jevinger and Jan A. Persson \\ Internet of Things and People Research Center, K2-The Swedish Knowledge Centre for Public Transport, \\ Department of Computer Science, Malmö University, Malmö 20506, Sweden; \\ banafsheh.hajinasab@mah.se (B.H.); johan.holmgren@mah.se (J.H.); ase.jevinger@mah.se (Å.J.); \\ jan.a.persson@mah.se (J.A.P.) \\ * Correspondence: paul.davidsson@mah.se; Tel.: +46-40-665-8618 \\ Academic Editors: Wijnand Veeneman and Eefje Cuppen \\ Received: 7 September 2016; Accepted: 24 November 2016; Published: 30 November 2016
}

\begin{abstract}
We investigate the opportunities and challenges of the forth wave of digitalization, also referred to as the Internet of Things (IoT), with respect to public transport and how it can support sustainable development of society. Environmental, economical, and social perspectives are considered through analysis of the existing literature and explorative studies. We conclude that there are great opportunities for both transport operators and planners, as well as for the travelers. We describe and analyze a number of concrete opportunities for each of these actors. However, in order to realize these opportunities, there are also a number of challenges that needs to be addressed. There are both technical challenges, such as data collection issues, interoperability, scalability and information security, and non-technical challenges such as business models, usability, privacy issues, and deployment.
\end{abstract}

Keywords: public transport; Internet of Things; digitalization; opportunities; challenges

\section{Introduction}

We are currently in what can be seen as the fourth wave of digitalization. The first wave came in the $80 \mathrm{~s}$ and consisted in the introduction of computers in many parts of society. In the $90 \mathrm{~s}$, the second wave in the form of the Internet made it easy to access and share information. The third wave is the mobile Internet that enables this regardless of where you are. With the fourth wave of digitization, it is not just people who use the Internet to access and share information, but also different types of entities, such as vehicles, appliances, and machinery. All parts of our society will be affected by this fourth wave, commonly referred to as the Internet of Things (IoT) [1].

Strongly related to IoT and the fourth wave of digitalization is the concept of ubiquitous computing first articulated by Mark Weiser at Xerox Parc more than 25 years ago [2]. His vision about calm technology requires computers to be imbedded into the environment in such a way that we use them without even thinking about their existence. This notion of computing enables users to use computers anywhere and anytime. In order to realize the envisioned ubiquitous computing by Mark Weiser, much research and development has been carried out on embedding computers into physical objects and to make them smarter (physical computing), connecting these smart objects to the Internet (Internet of Things), integrating computers with textile and clothes (wearable computing), distributing computation and user interface among several computing devices, etc.

Together with some other recent technological and methodological developments in information technology, such as open data, big data, sensor technology, and crowdsourcing, we argue that IoT can be seen as a powerful enabler of sustainable development in the context of public transport. In particular, the collection of different types of data can be made much easier, more accurate, and 
in real-time, through the use of IoT. Examples are data related to one or more of the following types of entities:

- Vehicles: location, occupancy level, vehicle status, presence of on-board staff, etc.

- Travelers: time and location of entering and leaving vehicles, individual preferences and final destination, ticketing data, etc.

- Infrastructure: the status of transport links, e.g., congestion, the number of people in a certain location, e.g., at a bus stop, etc.

The data can be either provided automatically through different types of sensors and machines, or via the travelers themselves through different types of smartphone applications. Such applications could either collect data automatically (e.g., position and velocity) or manually (e.g., travelers' preferences and their final destinations). The data can be gathered via dedicated travelers' information applications or via general applications such as Facebook. The availability of the abovementioned data, as well as other types of relevant data is increasing rapidly, and may be further accelerated by the voluntary provisioning of data by individual travelers. The efficient management and use of this large amount of data, often referred to as "big data" [3], are key issues for the ability to achieve the full potential of IoT, e.g., as an enable of more sustainable public transport. As the data typically is collected in real-time, it has the potential to impact real-time decisions by transport operators and travelers. However, the collected data is also highly relevant for the strategic planning of transports and the development of the transport system. In addition to just simply generate more data, IoT also has the potential to improve data quality, e.g., by fusing data from multiple sensors.

Moreover, IoT solutions can help the travelers to interact with the public transport system in a more efficient way through, e.g., supporting ticket purchasing and enabling the use of personalized and context-aware information services, such as traveler planners that make use of information such as, on which public transport vehicle the traveler is currently riding.

The potential in digitalization does not only concern collecting data and providing information about services. IoT is also a key ingredient for enabling remote control of vehicles and infrastructure, and even introducing autonomous action, e.g., autonomous vehicles that probably will be a vital part of the future public transport system.

In the context of public transport, digitalization can support the development of a more sustainable society in many ways, for example, the following:

- Environmental sustainability:

a. By optimizing routes, time-tables, style of driving, vehicle sizes, etc., the direct emissions from the public transport system can be reduced.

b. By increasing the attractiveness and use of public transport, it is possible to reduce the in-direct emissions (i.e., the emissions from the non-public transport system) and improving land use (e.g., reducing the space dedicated for car parking).

- Social sustainability:

c. By increasing accessibility to public transport for vulnerable groups (e.g., elderly, disabled, and ethnic minorities), it is possible to improve social equity in public transport.

d. By increasing the coverage of public transport services, equity and sustainable living is supported. In addition, by increasing the coverage of public transport, the access to different activities will increase, and therefore, the feeling of social inclusion and life satisfaction might increase.

e. By increasing public transport safety, personal safety can be improved. 
- Economical sustainability:

f. By optimizing the use of resources in public transport, money can be saved by the public transport providers.

g. By minimizing the travel time, the travelers can do more productive things than traveling and waiting for transport services.

In this article, we will investigate the opportunities as well as the challenges of the fourth wave of digitalization with respect to public transport and how the opportunities may contribute towards a sustainable society. There exist some previous analyses of the digitalization of public transport, such as $[4,5]$. Our contribution compared to those is that we take the recent developments in IoT and mobile Internet, as well as the sustainability perspective into account.

\section{Opportunities}

As mentioned in the introduction, the fourth wave of digitalization makes different types of data collection easier, more accurate, and in real-time. In addition, it provides a means for new types of remote control and automation. These developments enable new opportunities for nearly all aspects of public transport, including:

- Operations: opportunities from the transport operators' perspective.

- Planning: opportunities from the strategic transport planners' perspective.

- Travelling: opportunities from the travelers' perspective.

In this section, we will explore the opportunities from these three perspectives.

\subsection{Operations}

We refer to operations as the management of the resources used in public transport. In this subsection, we focus on the real-time aspects of operations, i.e., the actions and decisions that are not considered transport planning (see Section 2.2). Obviously, the data provided by IoT systems give new opportunities and can be used to support better resource utilization and better services in general.

In public transport systems, most transport services are timetabled, and an important opportunity is to use the real-time information enabled by IoT in order to deal with deviations from the original plan, i.e., in order to handle disturbances. Traditionally, the focus of action in such cases is to re-plan in order to restore the transport system according to the original plan and, e.g., get the stranded travelers to their destinations [6]. See [7] for an overview of the existing literature and discussions on this topic. In general, real-time data can improve the re-planning decisions through enabling the planners to base their decisions on more data and/or more accurate data. Moreover, IoT makes it possible to better communicate the taken actions to travelers and operators, e.g., through providing up-to-date information to the on-board staff on a train. However, re-planning actions and decisions might influence the sustainability both positively and negatively, which is why access to accurate, up-to-date information is important. For example, public transport may in fact increase emissions compared to using car travel, for example, if there are few passengers in a bus (in case of low fill rate).

Examples of opportunities:

- Improved management of operations based on knowledge about vehicles and travelers currently on, or planning to be on, a transport route, e.g., through ticketing data, sensor data, and data from travelers $[8,9]$.

Manage unplanned situations. Improved management may be of particular interest when unplanned situations occur, e.g., when a train departure is cancelled and needs to be replaced by bus, or when a vehicle is delayed. In such cases, decisions might need to 
be taken on how many replacement buses (or taxis) that should be used. Decisions might also need to be taken regarding re-allocation or re-scheduling of other vehicles. For example, decisions regarding whether a bus or train should wait for another delayed vehicle could be made with better information at hand, e.g., on how long is the expected waiting time and how many travelers are expected to board the waiting bus or train. IoT can in different ways provide information relevant for such decisions, which is useful (or necessary) for efficient traffic management, see for instance [10,11]. Examples of relevant information potentially provided by IoT are how many travelers are currently on a public transport vehicle and what are their intended destinations. See also [12] for early examples on methods on how to decide whether a train or a bus should wait or not for another vehicle. In terms of sustainability, unnecessary resource utilization may, potentially, be avoided (e.g., through minimizing the number of replacement vehicles). Hence, there is also a potential to reduce the direct emissions from public transport. In addition, we expect the passengers' waiting time, in the general case, to decrease due to improved disturbance management. In addition, the indirect emissions might eventually decrease as a consequence of the possibility to offer more robust, hence more attractive, public transport services that the travelers might prefer over the private car alternative.

- Demand Responsive Transport (DRT). In DRT, passengers share a vehicle, for instance a small bus, which picks up and drops off the passengers at passenger-specified locations and times [13]. Initially, DRT was designed for disabled or elderly people (see [14,15]). However, it is now seen as an interesting solution for increased access and flexibility in public transport, for the whole community $[16,17]$. In particular, it enables the use of more dynamic and flexible bus routes based on the passengers' preferences. For instance, a bus may only visit the bus stops where the travelers on the bus want to exit and where there are people actually waiting. Hence, DRT may provide improved sustainability in terms of increased accessibility and improved coverage. In the long run, DRT might also lead to reduced indirect emissions as a direct consequence of enabling more attractive, passenger adapted, public transport alternatives. Depending on the implementation, there is also a potential for decreased direct emissions of public transport, e.g., if buses are allowed to take shortcuts in order to avoid stops where no passengers are waiting, or if it is possible to replace large buses with smaller, more fuel-efficient, vehicles when demand is expected to be low. Depending on the implementation, and on the passengers behavior, it is also possible to achieve reduced travel times for the passengers by advising them to walk to nearby bus stops to minimize their waiting time or to catch a fast transport service.

- Maintenance-wear. Through the use of sensor data about the status of vehicles, it is possible to make more accurate decisions on when vehicles need maintenance, which may result in fewer scheduled and unscheduled stops for maintenance and repair, and potentially less maintenance time in total. See for instance [18] for an early sensor-based approach for vehicle maintenance. Improved sustainability may be achieved mainly in terms of improved resource utilization. Sustainability aspects that might be supported indirectly are safety and travel time. Safety might be improved through using vehicles in better condition (avoiding malfunctioning brakes, worn out tires, etc.) and by reducing the risk of dangerous evacuations (due to unscheduled stops) of the passengers, e.g., at roads with high traffic density. We expect unnecessary waiting time to be avoided due to fewer unscheduled stops. In addition, vehicles in need for maintenance, e.g., trains with damaged wheels and pantograph strips, might cause infrastructure damage that may cause delays and additional waiting time, which might be avoided, for other vehicles sharing the same infrastructure.

Maintenance-damage. Related to maintenance due to wear and tear, there is also a possibility to use IoT to collect information about damage on the vehicles and the 
infrastructure used in public transport. For example, travelers can submit reports on malfunctions, e.g., broken seats or broken seat belts, possibly together with context data collected from the vehicles. If the traveler receives immediate response, the traveler satisfaction may increase. A potential is to use crowdsourcing that enables the operator (in addition to other travelers) to take quick actions, such as, repairing damages, see for instance [19]. This type of systems might contribute to improved sustainability through reduced indirect emissions by enabling more attractive public transport services and through increased safety by achieving quicker identification and repair of safety critical equipment.

- Self-driving vehicles. Self-driving vehicles, which are enabled by IoT technology, may influence the transport system significantly [20,21]. Replacing drivers will reduce the cost and most probably also improve the safety of transport. Improved driving pattern, e.g., eco-driving, can be highly prioritized in the self-driving vehicles and hence lead to reduced emissions. An interesting opportunity that appears with self-driving cars is that they can be time-shared in a quite easy way, since the re-allocation to the next user can be achieved without involving human drivers. For instance, a user may rent a self-driving car for the weekends and the very same car may be used for public transport (i.e., as taxi) during the weekdays, and the user does not need to worry about the reallocation between the different purposes every week. In summary, self-driving cars may contribute to improved sustainability in terms of improved resource utilization and reduced emissions, and potentially improved safety depending on the implementation.

- Transport related services. In addition to enabling new services and improved decision making for the traditional public transport operators, IoT might create opportunities for transport-related services. Reduced travel time can be achieved, for instance, by providing information, for bike renters and taxi companies, that supports the efficient allocation of non-occupied bikes and taxis. Rental bikes can support more attractive public transport by, for example, enabling travelers to travel to and from bus stops and terminals using rented bikes. It is also possible to create services that help travelers find available taxis and bikes. For example, a successful approach with replacement taxis is applied in Munich [22]. Altogether, the abovementioned improvements may directly lead to reduced travel time and more attractive public services, hence supporting the sustainability aspect of reduced indirect emissions.

\subsection{Planning}

One of the major challenges in public transport is to plan the resources in such a way that they are best utilized for providing the best possible services to the travelers and for minimizing the negative implications of transport, including $\mathrm{CO}_{2}$ emissions and noise. The planning issues related to public transport includes, but are not limited to, choosing bus and train routes (or lines), determining frequencies and timetables of the vehicles that travel along the routes, and localization of stops. The planning issues might also concern decisions on implementing new technologies, such as ITS services in public transport. The difficulty of planning is often due to the lack of information feedback from the transport operations, i.e., the transport planners do not always have access to enough information, e.g., about individual trips in order to plan the transport resources in the best possible way. By increasing the use of IoT-based services in transport operations, there is a unique opportunity for transport planners to collect huge amounts of data ranging from travel behavior to infrastructure usage, which can be used to achieve improved planning of the public transport resources, including vehicles and infrastructure.

Transport modeling and simulation is one of the most common approaches for supporting the decision making in transport planning through, e.g., enabling to predict the impacts of new transport policies and infrastructure investments. Based on the questions that a simulation model needs to answer, different types of data, ranging from socio-demographic attributes of people to the transport network data, needs to be provided to the model. In the area of transport system modeling and 
simulation, there is an opportunity to access data that is automatically collected using, e.g., IoT devices, and to outsource some of the computations that traditionally are carried out within the simulation model, using open web services like Google Maps.

Examples of opportunities:

- An obvious opportunity for the transport planners is to retrieve new types of data, or more accurate data, through the use of IoT systems, smartphones, and crowdsourcing systems. The retrieved information could be used to support tasks such as, determining optimal bus routes and timetables, in a better way than is typically possible today.

Collection of traveler data. Smartphone applications can be used to extract movement patterns of their owners and to identify, for example, the chosen transport mode, i.e., car, bus, bike, walking, etc. [23,24]. Examples of other types of data that may be captured in similar ways are which transport services individual travelers use, and when they enter and leave services. In terms of improved sustainability, this type of data may be used to enable better utilization of transport resources, for example, through supporting the design of more efficient routes, which is expected to result in reduced emissions from the vehicles used in public transport, i.e., our direct emissions sustainability aspect. Other sustainability aspects that might be supported, depending on which aspects are considered in the route design process are accessibility, coverage, and travel time. As a consequence of improved routes, there is also a potential to support the indirect emissions aspect. However, we expect this to be highly dependent on whether the improved public transport routes, enabled through the use of travel data, appeals to the travelers that traditionally prefer the private car alternative.

Collection of vehicle data. On the vehicle level, the use of IoT makes it is possible to automatically collect detailed travel data on, e.g. when passengers enter and leave vehicles, occupancy rates (e.g., by measuring the number of available seats through sensors), and robustness (frequent delays). Realistic and high quality data of the abovementioned types might be valuable for travel planners in order to improve the planning of the resources used in public transport. Improved resource utilization and reduced direct emissions can be achieved through using information about the current use of vehicles, e.g., by using mini-buses at times where few travelers are expected. However, we believe there is a risk that public transport becomes less attractive if vehicle data is used to support decisions on choosing "too" small buses. On the other hand, there is a potential to reduce indirect emissions through designing more attractive services, e.g., by using extra buses at times where the buses are typically crowded.

- Collection of traffic data. Online traffic monitoring [25,26], e.g., measuring congestion levels through crowdsourcing and road-side cameras, might give input that can be used to reduce the direct emissions and travel times of public transport, e.g., through supporting the generation of improved routes, where congested roads might be avoided. Traffic data can also make public transport more attractive by supporting the design of services along routes where driving is often slow due to heavy congestion, perhaps utilizing bus lanes, hence indirectly contributing to reduced indirect emissions. In addition, there is a potential to use traffic data to improve personal security, our safety sustainability aspect, for example, through supporting decisions on building safer bus stops along roads that are dangerous due to, e.g., high congestion or high driving speeds.

Collection of air quality data. Air pollution monitoring $[27,28]$ provide information that might be used to identify the need for more environmentally friendly transport services, for example, using public transport vehicles that produce less emissions. It may also support decisions regarding the introduction of public transport services that travelers might prefer over private car transport in areas with bad air quality. Through making the 
decision makers aware about air quality problems in particular areas, this type of data can be used to support sustainability mainly in terms of direct emissions.

- Collection of transfer point data. Detailed information about transfer points between services can be used to support optimization of timetables so that travelers in a better way than today can utilize routes involving multiple public transport services. An example of relevant transfer point data is data about people movements captured by different types of sensors. Transport services that are connected in a better way may reduce the overall travel time, hence improving the economical sustainability for the travelers. As a consequence of improved timetables, transfer point data can also support sustainability by reducing the emissions from non-public transport through enabling more attractive public transport services. In addition, information about transfer points might be used to support decisions on adapting transfer points to elderly and weak traveler groups, hence improving accessibility.

- Use online services for modeling. Using online services to access the data collected by IoT devices and smartphones (including crowdsourcing systems) as well as of different types of processed data, there is an opportunity to construct analysis and problem solving models that work with data in a new way [29]. For example, transport simulation models for analysis of public transport might use online services in order to access, e.g., weather data and current travel times, collected by different types of IoT sensors. A special type of online service, which is relevant to mention here is travel planner systems. Travel planner systems, mainly smartphone applications, are becoming more widespread, and we find it reasonable to assume that the choices of travelers' to some extent is changing based on suggestions provided by such systems. Therefore, we believe that the use of travel planners to estimate people's travel behavior can increase the accuracy of the travel behavior modeling in simulation systems. In terms of planning, we argue that the use of online services has the potential to influence all types sustainability aspects discussed above, however, indirectly through the use of the output from various types of models.

\subsection{Travelling}

A common problem of today is that the travelers often are unable to make informed choices due to lack of information, or due to lack of up-to-date information. Efficient approaches need to be developed in order to provide travelers with the correct information in their current situations. Such information may concern, for instance, what travel options are actually available in a given situation, where tickets can be bought, and what support a specific transport service offers to elderly or disabled persons. By providing enhanced information and services through IoT, the behavior of the travelers may change; with more information at hand, people are able to make more informed travel decisions, and old travel habits following the same patterns can be broken. In particular, enhanced information and services have the potential to increase the attractiveness of public transport, which may encourage more travelers to choose public transport over the car and in that way contribute to improved sustainability.

IoT technology can be used in different ways to collect data for traveler services. For instance, delay information can be obtained from recognition or positioning sensors on-board vehicles and at stops [5], information about the travelers' actual destinations (used to provide efficient transport alternatives) can be collected from smart card tickets [30], and micro-navigation information can be attained using IoT-based recognition systems that are located on-board vehicles and across stations [31]. In some situations, data similar to those collected already exist in other types of systems. However, IoT provides an opportunity to increase the level of detail and the accuracy of the data. For instance, the positioning system available in smart phones can typically not be used for detailed indoor navigation guidance, both because the accuracy of the positioning data may be too low and because indoor facilities are not taken into account. Instead, context-aware information systems provided by IoT technology might be used to provide accurate indoor navigation guidance. 
Examples of opportunities:

- Real-time delay information. Based on information about delayed or cancelled transport services, and about the context, the traveler is able to make informed decisions on which transport service to select during a disturbance. A service for supporting such decisions can be made personalized though the use of information about the current location of the traveler, e.g., on which bus or terminal the traveler currently is located [31]. Thereby, alternative travel routes can be suggested to the traveler. Hence, the real-time delay information supports the travel time sustainability aspect by helping the travelers to reach their destinations with minimum delay during disturbance. Eventually, improved real-time delay information might also support the reduction of indirect emissions by offering transport services that are more predictable, and therefore more attractive. Moreover, travelers with specific needs, e.g., elderly or disabled, can receive customized real-time information about transport alternatives with high accessibility. Real-time information about delays can be provided using IoT technology, e.g., by devices at each bus stop that recognize if the bus has stopped there [32].

- Co-traveler information. Information about which passengers are travelling on the same vehicle can be provided using IoT, e.g., through the use of beacons. This information can be used for connecting people and, together with information about the passengers' destinations, enable shared taxis both during disturbance and to reach the final destination in case this is not possible using bus or train. In terms of sustainability, improved co-traveler information, enabled through the use of IoT is expected to contribute to improved resource utilization and indirectly reduced travel time. We make the assumption that by sharing taxis, resources are indirectly saved and emissions are indirectly reduced in the transport system. We also expect that the indirect emissions will decrease as a consequence of enabling a more attractive service, where people can connect without too much effort. Moreover, this type of service might be of particular value during disturbances.

- Real-time vehicle information. Real-time vehicle information concerns the possibility to make informed decisions on which public transport service to select, based on information about the status and characteristics of the vehicles used in public transport. Firstly, information about the number of passengers on-board a transport vehicle can be utilized by travelers to identify overcrowded vehicles [33]. For instance, they may choose to travel by bicycle instead of waiting for an overcrowded bus. Secondly, with real-time information about the characteristics and status of specific transport vehicles, people with special needs, such as elderly and disabled, can be informed about relevant transport possibilities. This type of information can be directed both to on-board passengers and to people waiting for transport, through the use of IoT. The information can be used for, e.g., informing a traveler of whether a specific bus has support and room for wheelchairs or baby strollers, or whether bicycles are allowed on a specific train waiting on a track. Obviously this type of information has an impact on the accessibility but also on the attractiveness of using public transports. Further it may enable travelers to avoid choosing a vehicle, where there is no available space, and thereby being able to reach their final destinations in less time than without this information.

- Delay compensation. Price compensation for delays due to disturbances can more easily be provided if the travelers are able to prove their presence on a delayed vehicle. This can be enabled by context-aware data provided by IoT. We expect that delay compensation will contribute indirectly (i.e., eventually) to reduced indirect emissions, as the possibility to get compensation might be a factor to choose public transport despite the, often high, risk for delays.

- Interchange guidance. Context-aware provision of information during interchanges can help guiding the traveler, for instance in order to reach the correct train platform or the ticket office, and to help calculating the time required for getting there [32,34]. It is also possible to take into account personal disability constraints, e.g., need for wheelchair. Hence, interchange guidance 
information may affect the accessibility sustainability aspect, and indirectly the travel time aspect if the times for (planned) interchange are reduced as consequence.

- Ticket-buying support. Ticket-buying support involves the ticketing and payment systems with which the traveler may interact. IoT technology can be used to provide positioning information in order to facilitate ticket purchasing. Furthermore, the validity of tickets can automatically be prolonged during disturbances. Easy and efficient ticketing systems influence the attractiveness of the public transport system. Further, it may reduce the time needed for purchasing tickets and thereby contributing to reduced the travel time if implemented correctly, and it may make it easier for travelers with special needs, e.g., children and intellectually disabled, to use public transport.

- Support during travel. Support during travel makes it possible for travelers to make sure that they are acting as planned, e.g., to get confirmation of that they have boarded the correct vehicle, that their tickets are valid, and getting information about when to leave the vehicle, by use of IoT technology [31,35]. Such support can make the public transport system more attractive and potentially also more accessible to larger groups of people (e.g., disabled persons). In addition, by avoiding getting off at the wrong location, the travel times may indirectly be reduced.

- Enriched travel experience. By providing different types of data enriching the travelling experience, public transport can be made more attractive. This may include providing contextual information about the destination or the current surroundings, or providing vehicle data that help travelers to keep track of the environmental load caused by their travel and possibly comparing this load to the load caused by the corresponding car travel.

\subsection{Discussion}

In Table 1, we summarize how the opportunities discussed in Sections 2.1-2.3 support the sustainability aspects presented in Section 1. In the table, " $\mathrm{D}$ " denotes expected direct influence, " $\mathrm{I}$ " expected indirect influence, typically not happening immediately and typically being a consequence of other effects, and parentheses indicate potential influence that is highly depending on the implementation. It should be emphasized that for the planning opportunities, we did not consider the time aspect when categorizing an effect as direct or indirect; we only considered whether the effect is expected as a consequence of other effects (indirect) or not (direct).

Table 1. Summary of how the identified opportunities supports the sustainability aspects.

\begin{tabular}{|c|c|c|c|c|c|c|c|}
\hline Opportunity/Sustainability Aspect & $\begin{array}{c}\text { Direct } \\
\text { Emissions }\end{array}$ & $\begin{array}{c}\text { Indirect } \\
\text { Emissions }\end{array}$ & Accessibility & Coverage & Safety & Resources & $\begin{array}{c}\text { Travel } \\
\text { Time }\end{array}$ \\
\hline Operations: manage unplanned situations & (D) & I & & & & (D) & $\mathrm{D}$ \\
\hline Operations: demand-responsive transport & (D) & $\mathrm{D}$ & (D) & $\mathrm{D}$ & & & (D) \\
\hline Operations: maintenance—wear & & & & & I & $\mathrm{D}$ & I \\
\hline Operations: maintenance-damage & & $\mathrm{D}$ & & & $\mathrm{D}$ & & \\
\hline Operations: self-driving vehicles & $\mathrm{D}$ & & & & (D) & $\mathrm{D}$ & \\
\hline Operations: transport related services & & $\mathrm{D}$ & & & & & $\mathrm{D}$ \\
\hline Planning: collection of traveler data & $\mathrm{D}$ & (I) & (D) & (D) & & $\mathrm{D}$ & (D) \\
\hline Planning: collection of vehicle data & $\mathrm{D}$ & (I) & & & & $\mathrm{D}$ & \\
\hline Planning: collection of traffic data & $\mathrm{D}$ & I & & & (D) & & $\mathrm{D}$ \\
\hline Planning: collection of air quality data & I & $\mathrm{I}$ & & & & & \\
\hline Planning: collection of transfer point data & & (D) & $\mathrm{D}$ & & & & $\mathrm{D}$ \\
\hline Planning: use online services for modeling & (I) & (I) & (I) & (I) & (I) & (I) & (I) \\
\hline Travelling: real-time delay information & & I & (D) & & & & $\mathrm{D}$ \\
\hline Travelling: co-traveler information & (I) & I & & & & $\mathrm{D}$ & I \\
\hline Travelling: real-time vehicle information & & (I) & $\mathrm{D}$ & & & & (D) \\
\hline Travelling: delay compensation & & I & & & & & \\
\hline Travelling: interchange guidance & & I & $\mathrm{D}$ & & & & I \\
\hline Travelling: ticket-buying support & & I & $\mathrm{D}$ & & & & (I) \\
\hline Travelling: support during travel & & I & (D) & & & & (I) \\
\hline Travelling: enriched travel experience & & I & & & & & \\
\hline
\end{tabular}

From our analysis of the identified opportunities, we see that the fourth wave of digitalization has a large potential to support sustainable development of public transport in a wide range of ways. 
Further analysis is needed in order to assess the relative size of the influence on sustainability for the different opportunities. However, our analysis suggests that demand-responsive transport and collection of traveler data would have the most significant direct impact on several sustainability aspects. Further, we provide guidance of what opportunities to potentially implement in order to support a specific sustainability aspect. For instance, we can see that there are rather few opportunities that we expect to support coverage, whereas most opportunities support the indirect emissions category, i.e., through increasing the usage of public transport. In addition, by assessing the type of influence, e.g., direct, indirect and the dependency on implementation, we argue that careful analysis of alternatives of implementation is needed for a number of opportunities that we assess as highly dependent. We can also argue that for the cases of indirect influence, additional analysis is motivated since the uncertainty is increased in case of dependency on other effects.

\section{Challenges}

In this section, we discuss some important challenges related to the use of the fourth wave of digitalization (i.e., IoT) within public transport as a successful enabler for a sustainable society (see a discussion on opportunities in Section 2). We discuss the challenges in relation to the following categories: business models, privacy and integrity issues, security, interoperability, scalability, usability, data collection, and deployment.

Obviously, there exist technologies that partially, or at least in some situations, help overcome the identified challenges; some examples of useful technologies are given below. However, it cannot be claimed that any existing solution completely eliminates any of the identified challenges in all possible situations, in particular, since the involved actors' knowledge on existing technologies may complicate their application in order to overcome the discussed challenges.

In order to address the challenges listed below, one should review relevant previous work, especially in the area of Intelligent Transport Systems (ITS). In particular, a number of general ITS architectures, which face different challenges and technological developments, have been proposed. These architectures are on a relatively high level of abstraction, meaning that they are technology-independent specifications on components and communications [36]. Thus, some of the interoperability challenges discussed below may be solved by using one of these ITS architecture. However, there is no single "standard" ITS architecture; different countries and regions have developed their own ITS architectures in order to fit their needs [37]. This lack of a single standard ITS architecture must be handled to develop global solutions.

For the other challenges identified in this paper, the high-level architectures typically do not provide any solutions. However, Dimitrakopoulos and Demestichas [38] describe an example of how to concretize an ITS architecture using the concept of Cognitive Transport Network. The system is based on cognitive and wireless sensor networks (WSNs), and it provides directives to both drivers and infrastructure elements, e.g., traffic lights, with the aim of improving transport efficiency and safety. In particular, it involves a transportation management system with cognitive learning capabilities, which use the data from the WSN to create knowledge and experience about the current and past situations in the transport network. Based on this information, any new decisions taken, including future planning, are improved in terms of performance and reliability [38]. The study is focused on car drivers; however, parallels can be drawn to IoT-based public transport. By using sensor data, in combination with cognitive transport management systems in an IoT-based environment, both planning and operations in public transport can be improved.

In this paper we will not further address technical solutions, since we focus on identifying opportunities and challenges rather than on how to build systems.

\subsection{Business Models}

In order to achieve the full benefits of the fourth wave of digitalization, involvement is typically required by a multitude of actors in addition to the public transport operator, including 
telecommunication operators, sensor data providers, data storage providers, end-user service providers, and the travelers themselves, but also different public authorities. Large investments may be needed in order to build and maintain the necessary infrastructure, the collected data needs to be managed and stored, services and data APIs needs to be provided, etc.

Obviously, the building and maintenance of IoT systems are associated with significant costs for the involved actors; costs that need to be covered for in a reasonable way, in particular since many types of actors are needed in order to enable an efficient IoT system. A major challenge is the need for effective business models, which regulates how the revenues should be distributed in order to cover for the costs of the involved actors. In particular, business models need to regulate the distribution of costs and revenues for sharing and using the collected data and the generated information, and for providing services for end users, companies and other organizations. It is important that there are business opportunities for the companies who want to provide the necessary services but are out of the scope of the transport operators and public authorities; they need to get a return of their investments.

It should be further emphasized that it appears to be easier to get paid the closer to the customer/user one is in the information chain. In the public transport area there are some open data sources, as well as platforms for services (cf. www.trafiklab.se). However, a major challenge concerns how to get paid for commercially gathering of data. Bulger et al. provide a thorough discussion on business models concerning large amounts of data, i.e., "big data" [39].

Since public transport operations are typically under the tight regulation and procurement from governmental agencies, it may be enforced that some data needs to be supplied by the transport operators. However, challenges of, for instance continuity and quality is often an issue and initiatives of other pure commercial and third party actors typically need business models.

\subsection{Privacy and Integrity Issues}

Privacy is about not sharing data about organizations and individuals, whereas integrity concerns protecting against unauthorized modification of data. In the context of public transport, privacy often concerns not sharing any information about the travels of individuals. For instance, the movement of individual travelers can be tracked by data from mobile phone operators or through the use of RFID tags in travel cards (data which is very useful for generating Origin-Destination matrices).

In a reality where various types of sensors continuously monitor and record the activities of people and items, and where end users submit information about their activities, there are challenges of how to protect the privacy and integrity of the individuals that are being monitored. To gain the trust of the travelers it is important that no personal information is used or distributed without explicit consent.

Challenges include:

- Securing stored and communicated data against unauthorized access (both regarding disclosure and altering of the collected data), for example, using cryptography and access control in different ways.

- Anonymizing the collected data without losing the possibility to trace the activities of individuals, which might be needed to make strong analyses, for example, in order to achieve improvements of the public transport system. See Fung et al. [40] for a general survey on methods for privacy-preserving data publishing, which relates to this type of challenges. In addition, Ziegeldorf et al. [41] provide a general discussion on threats and challenges related to privacy in IoT systems.

\subsection{Security}

Unfortunately, there are many types of potential malicious actors that, for various reasons, may attack the information systems of public transport, such as cyber-terrorists and hackers. In addition, 
there are competitors, e.g., providers of public transport services that have business interests in sub-optimal operations.

The challenge related to security is quite general: How is it possible to make it more difficult for malicious actors? The state-of-the-art of security as well as privacy of IoT is covered by Sicari et al. [42].

\subsection{Interoperability}

Interoperability concerns the ability of systems to work together, which is of particular importance in machine-to-machine contexts, such as IoT, where sensors and other types of devices to a large extent communicate without the involvement of humans. As the IoT is characterized by a largely heterogeneous blend of connected devices, provided by different vendors using different types of technology, we predict that interoperability issues will constitute some of the main challenges for a well-functioning, connected IoT infrastructure.

Challenges related to interoperability include the development and usage of standardized protocols and interfaces for communication and service provision (e.g., standard web service protocols), as well as the development of efficient middleware.

\subsection{Scalability}

In the context of IoT, scalability is the ability of a system to function with growing number of users, and sensors and devices that continuously collect and process large amounts data. As mentioned earlier, the efficient management and use of this data is often referred to as "big data". Storing and processing data is not always a huge issue when the amount of data is small, but as the amount of data that needs to be stored and analyzed increases very fast with the roll-out of IoT, there are some major challenges related to the scalability, such as:

- How to store all the collected data in a way that privacy and integrity is preserved (cf. Section 3.2).

- How to analyze and process all of the collected data to transfer it into meaningful information that can be used by various types of actors, for example, travelers and transport operators.

In some cases, the amount of data is so huge that it might not even be possible to store all the collected data. In addition, privacy and integrity issues might prohibit the storage of sensitive data. Instead, there is in some situations a need to analyze data in real time.

Another challenge related to the huge amount of collected data, which perhaps cannot be stored, is how to properly aggregate data in a way that, for example, researchers can use it for future analysis. For example, statistical distributions can be an important way to store data.

There is also a need for efficient algorithms and models that can be used for analysis of the collected data and for solving problems (e.g., using simulation and mathematical optimization). Due to the complexity of many optimization problems, there is a need for efficient heuristics that can be used to solve optimization problems (often in real time).

\subsection{Usability}

In the context of IoT as an enabler for sustainable public transport, we consider usability as how easy it is for the involved actors to make use of the provided information and services (including the generation of data, e.g., via crowdsourcing). For example, the travelers typically access public transport planners through smartphone applications and interactive web pages, which need to be easy to use and to learn.

High usability is a prerequisite for achieving the benefits of IoT and is important in particular in order to reach the travelers. If the interaction is not intuitive, the services will not be used. 
Challenges related to usability include:

- How to present data and information in a way that humans and machines can easily use the information.

- How to design appropriate interaction models so that the users can interact with services and devices in an intuitive way.

For example, it is important to be able to use a public transport planner smartphone application without knowing the names of the departure and arrival bus stops.

Research and innovation within fields such as interaction design aim at facing the challenges related to usability, and general findings in this field obviously give input to building user-friendly systems within public transport.

\subsection{Data Collection}

As mentioned above, IoT can be seen as a powerful enabler of sustainable development in the context of public transport through enabling improved possibilities for data collection. However, a number of challenges are related to the actual collection of data, e.g.,

- Determining what type of data is possible to collect, both in real-time and in retrospect.

- Identifying what type of data is actually useful for the different actors in different situations.

- Collecting and storing data in the best and most efficient way. This may include non-traditional methods like crowdsourcing and using social networks like Twitter.

- How to ensure that the collected data is of sufficient quality. Data can be incorrect due to several reasons, for example, that the IoT sensors might be of poor quality or that there are individuals who intentionally want to spoof the sensors or in other ways communicate incorrect data. Hence, there is a need for methods that can be used to identify errors and inconsistencies in the collected data.

- How to handle situations with insufficient quantity of data. It is important not to base decisions on data that is too scarce.

\subsection{Deplyoment}

In order to realize the full potential of some of the opportunities listed above, it is necessary that a majority of the users have adopted the implemented IoT solutions. Thus, this challenge concerns the user acceptance of new technologies and services, which in addition to the acquisition of necessary equipment, e.g., a smartphone, may also require changed behaviors. Moreover, related to the privacy and integrity issues mentioned above, the IoT solutions usually collect data from the users through sensors or manually, requiring the users to be willing to share data.

To improve user acceptance, there have been efforts to make users involved in the design and deployment processes. For instance, the concept of living labs has recently been established as a new way of testing and evaluating new systems in a user-centered environment [43]. It can be argued that new generations of systems can be deployed in a smaller scale in a living lab in order to assess the user acceptance and technological challenges.

Obviously, not only the citizens need to change their use of technology and behavior. Also the transport providers and administrative sector need to adapt to the new technology and services.

\section{Conclusions}

We have analyzed the opportunities as well as the challenges of the fourth wave of digitalization with respect to public transport and how it can support sustainable development of society, both from environmental, economical, and social perspectives. 
The conclusion is that there are great opportunities for both transport operators and strategic transport planners, as well as, for the travelers. Some of these opportunities have been well explored, and others have a great potential to be realized.

Moreover, we have identified a number of challenges that needs to be addressed, both technical, such as data collection issues, interoperability, scalability and information security, and non-technical, such as business models, usability, privacy issues, and deployment.

From organizational perspectives there needs to be a deeper understanding of the specific needs and potential of information and ICT solutions for the different public transport stakeholders, i.e., operators, planners, different groups of customers, and public authorities.

Acknowledgments: This research was partially funded by K2-the Swedish Knowledge Centre for Public Transport, and the Knowledge Foundation through the Internet of Things and People research profile.

Author Contributions: All authors contributed equally to the research described in the article and to the writing of the article.

Conflicts of Interest: The authors declare no conflicts of interest.

\section{References}

1. Atzori, L.; Iera, A.; Morabito, G. The Internet of Things: A survey. Comput. Netw. 2010, 54, $2787-2805$. [CrossRef]

2. Weiser, M. The computer for the 21st century. Sci. Am. 1991, 265, 94-104. [CrossRef]

3. Chen, M.; Mao, S.; Liu, Y. Big Data: A Survey. Mobile Netw. Appl. 2014, 19, 171-209. [CrossRef]

4. Blythe, P.; Rackliff, T.; Holland, R.; Mageean, J. ITS Applications in Public Transport: Improving the service to the transport system. J. Adv. Transp. 2000, 34, 325-345. [CrossRef]

5. Camacho, T.; Foth, M.; Rakotonirainy, A. Pervasive Technology and Public Transport: Opportunities beyond Telematics. IEEE Perv. Comput. 2013, 12, 18-25. [CrossRef]

6. Darmanin, T.; Lim, C.; Gan, H. Public Railway Disruption Recovery Planning: A new recovery strategy for metro train Melbourne. In Proceedings of the 11th Asia Pacific Industrial Engineering and Management Systems Conference, Melaka, Malaysia, 7-10 December 2010.

7. Jespersen-Groth, J.; Potthoff, D.; Clausen, J.; Huisman, D.; Kroon, L.; Maróti, G.; Nielsen, M.N. Disruption Management in Passenger Railway Transportation. In Robust and Online Large-Scale Optimization, LNCS; Ahuja, R., Möhring, R., Zaroliagis, C., Eds.; Springer International Publishing: Berlin, Germany, 2009; Volume 5868, pp. 399-421.

8. Bagchi, M.; White, P.R. The potential of public transport smart card data. Transp. Policy 2005, 12, 464-474. [CrossRef]

9. Kostakos, V.; Camacho, T.; Mantero, C. Towards proximity-based passenger sensing on public transport buses. Pers. Ubiquit. Comput. 2013, 17, 1807-1816. [CrossRef]

10. Jin, J.G.; Teo, K.M.; Odoni, A.R. Optimizing bus bridging services in response to disruptions of urban transit rail networks. Transp. Sci. 2015, 50, 790-804. [CrossRef]

11. Ibarra-Rojas, O.J.; Delgado, F.; Giesen, R.; Muñoz, J.C. Planning, operation, and control of bus transport systems: A literature review. Transp. Res. B Meth. 2015, 77, 38-75. [CrossRef]

12. Ginkel, A.; Schöbel, A. To wait or not to wait? The bicriteria delay management problem in public transportation. Transp. Sci. 2007, 41, 527-538. [CrossRef]

13. Ronald, N.; Thompson, R.; Haasz, J.; Winter, S. Determining the Viability of a Demand-Responsive Transport System under Varying Demand Scenarios. In Proceedings of the 6th ACM SIGSPATIAL International Workshop on Computational Transportation Science, Orlando, FL, USA, 5-8 November 2013.

14. Broome, K.; Worrall, L.; Fleming, J.; Boldy, D. Evaluation of flexible route bus transport for older people. Transp. Policy 2012, 21, 85-91. [CrossRef]

15. Dikas, G.; Minis, I. Scheduled paratransit transport systems. Transp. Res. B Meth. 2014, 67, 18-34. [CrossRef]

16. Nelson, J.D.; Wright, S.; Masson, B.; Ambrosino, G.; Naniopoulos, A. Recent developments in Flexible Transport Services. Res. Trans. E 2010, 29, 243-248. [CrossRef] 
17. Dias, A.; Telhada, J.; Carvalho, M.S. Simulation approach for an integrated decision support system for demand responsive transport planning and operation. In Proceedings of the 10th Annual Industrial Simulation Conference, Brno, Czech Republic, 4-6 June 2012.

18. Capriglione, D.; Liguori, C.; Pietrosanto, A. Analytical redundancy for sensor fault isolation and accommodation in public transportation vehicles. IEEE Trans. Instrum. Meas. 2004, 53, 993-999. [CrossRef]

19. Lau, S.L.; Ismail, S.S. Towards a real-time public transport data framework using crowd-sourced passenger contributed data. In Proceedings of the 82nd IEEE Vehicular Technology Conference, Boston, MA, USA, 6-9 September 2015.

20. Narla, S.R.K. The evolution of connected vehicle technology: From smart drivers to smart cars to... self-driving cars. ITE J. 2013, 83, 22-26.

21. Brownell, C.; Kornhauser, A. A Driverless Alternative-Fleet Size and Cost Requirements for a Statewide Autonomous Taxi Network in New Jersey. Transp. Res. Rec. 2014, 2416, 73-81. [CrossRef]

22. Zeng, A.Z.; Durach, C.F.; Fang, Y. Collaboration decisions on disruption recovery service in urban public tram systems. Transp. Res. E 2012, 48, 578-590. [CrossRef]

23. Stenneth, L.; Wolfson, O.; Yu, P.S.; Xu, B. Transportation mode detection using mobile phones and GIS information. In Proceedings of the 19th ACM SIGSPATIAL International Conference on Advances in Geographic Information Systems, Chicago, IL, USA, 1-4 November 2011.

24. Xia, H.; Qiao, Y.; Jian, J.; Chang, Y. Using smart phone sensors to detect transportation modes. Sensors 2014, 14, 20843-20865. [CrossRef] [PubMed]

25. Artikis, A.; Weidlich, M.; Schnitzler, F.; Boutsis, I.; Liebig, T.; Piatkowski, N.; Gal, A.; Mannor, S.; Kinane, D.; Gunopulos, D. Heterogeneous Stream Processing and Crowdsourcing for Urban Traffic Management. In Proceedings of the 17th International Conference on Extending Database Technology, Athens, Greece, 24-28 March 2014.

26. Heipke, C. Crowdsourcing geospatial data. J. Photogramm. Remote Sens. 2010, 65, 550-557. [CrossRef]

27. Andersen, A.B.; Krøgholt, P.; Bierre, S.; Tabard, A. NoxDroid on a Ride in the Inner City of Copenhagen. 2012. Available online: http://noxdroid.org/ (accessed on 27 June 2016).

28. Aoki, P.M.; Honicky, R.J.; Mainwaring, A.; Myers, C.; Paulos, E.; Subramanian, S.; Woodruff, A. Common sense: Mobile environmental sensing platforms to support community action and citizen science. In Proceedings of the 10th International Conference on Ubiquitous Computing, Seoul, Korea, 21-24 September 2008.

29. Hajinasab, B.; Davidsson, P.; Holmgren, J.; Persson, J.A. On the use of on-line services in transport simulation. In Proceedings of the International Symposium of Transport Simulation, Jeju, Korea, 29 August2 September 2016.

30. Van der Hurk, E.; Kroon, L.; Maroti, G.; Vervest, P. Deduction of Passengers' Route Choices from Smart Card Data. IEEE Trans. Intell. Transp. 2015, 16, 430-440. [CrossRef]

31. Foell, S.; Kortuem, G.; Rawassizadeh, R.; Handte, M.; Iqbal, U.; Marron, P. Micro-navigation for Urban Bus Passengers: Using the Internet of Things to improve the public transport experience. In Proceedings of the 1st International Conference on IoT in Urban Space, Rome, Italy, 27-28 October 2014.

32. Doukas, C.; Metsis, V.; Becker, E.; Le, Z.; Makedon, F.; Maglogiannis, I. Digital cities of the future: Extending @home assistive technologies for the elderly and the disabled. Telemat. Inform. 2011, 28, 176-190. [CrossRef]

33. Farkas, K.; Nagy, A.Z.; Tomás, T.; Szabó, R. Participatory sensing based real-time public transport information service. In Proceedings of the 2014 IEEE International Conference on Pervasive Computing and Communications Demonstrations, Budapest, Hungary, 24-28 March 2014.

34. Flores, G.; Cizdziel, B.; Manduchi, R.; Obraczka, K.; Do, J.; Esser, T.; Kurniawan, S. Transit Information Access for Persons with Visual or Cognitive Impairments. Computers Helping People with Special Needs. In Computers Helping People with Special Needs, LNCS; Miesenberger, K., Fels, D., Archambault, D., Peňáz, P., Zagler, W., Eds.; Springer International Publishing: Berlin, Germany, 2014; Volume 8547, pp. 403-410.

35. Garcia, C.R.; Candela, S.; Ginory, J.; Quesada-Arencibia, A.; Alayon, F. On Route Travel Assistant for Public Transport Based on Android Technology. In Proceedings of the 6th International Conference on Innovative Mobile and Internet Services in Ubiquitous Computing, Palermo, Italy, 4-6 July 2012.

36. Zuzana, B.; Bureš, P.; Jesty, P. Intelligent transport system architecture different approaches and future trends. In Data and Mobility; Düh, J., Hufnagl, H., Juritsch, E., Pfliegl, R., Schimany, H., Schönegger, H., Eds.; Springer: Berlin/Heidelberg, Germany, 2010; Volume 81, pp. 115-125. 
37. Williams, B. Intelligent Transport Systems Standards; Artech House: London, UK, 2008.

38. Dimitrakopoulos, G.; Demestichas, P. Intelligent transportation systems based on cognitive networking principles and management functionality. IEEE Veh. Technol. Mag. 2010, 1, 77-84. [CrossRef]

39. Bulger, M.; Taylor, G.; Schroeder, R. Data-Driven Business Models: Challenges and Opportunities of Big Data, Oxford Internet Institute. 2014. Available online: http:/ /www.nemode.ac.uk (accessed on 28 August 2016).

40. Fung, B.C.M.; Wang, K.; Chen, R.; Yu, P.S. Privacy-Preserving Data Publishing: A Survey of Recent Developments. ACM Comput. Surv. 2010, 42, 7. [CrossRef]

41. Ziegeldorf, J.H.; Morchon, O.G.; Wehrle, K. Privacy in the Internet of Things: Threats and challenges. Secur. Commun. Netw. 2014, 7, 2728-2742. [CrossRef]

42. Sicari, S.; Rizzardi, A.; Grieco, L.A.; Coen-Porisini, A. Security, Privacy and Trust in Internet of Things: The road ahead. Comput. Netw. 2015, 76, 146-164. [CrossRef]

43. Schaffers, H.; Sällström, A.; Pallot, M.; Hernández-Muñoz, J.M.; Santoro, R.; Trousse, B. Integrating Living Labs with Future Internet experimental platforms for co-creating services within Smart Cities. In Proceedings of the 17th International Conference on Concurrent Enterprising (ICE), Aachen, Germany, 20-22 June 2011; pp. 1-11.

(C) 2016 by the authors; licensee MDPI, Basel, Switzerland. This article is an open access article distributed under the terms and conditions of the Creative Commons Attribution (CC-BY) license (http://creativecommons.org/licenses/by/4.0/). 